\title{
Correction to: Ultrasound-guided renal transplant biopsy: practical and pragmatic considerations
}

\author{
Maitray D. Patel ${ }^{1} \cdot$ Scott W. Young ${ }^{1} \cdot$ J. Scott Kriegshauser ${ }^{1} \cdot$ Nirvikar Dahiya $^{1}$
}

Published online: 7 December 2018

(C) Springer Science+Business Media, LLC, part of Springer Nature 2018

\section{Correction to:}

Abdom Radiol (2018) 43:2597-2603

https://doi.org/10.1007/s00261-018-1484-5

The original version of this article unfortunately contained an error. Though one of the coauthor names correctly appeared in the published version, it is incorrectly displayed in indexing sites due to a tagging error in metadata.

The purpose of this Correction article is to correct the metadata as,

Given name: J. Scott

Surname: Kriegshauser

The original article can be found online at https:// doi.org/10.1007/s00261-018-1484-5.

Maitray D. Patel

patel.maitray@mayo.edu

1 Department of Radiology, Mayo Clinic Arizona, 5777 E.

Mayo Blvd, Phoenix, AZ 85054, USA 